\title{
EDUCAÇÃO EM CIÊNCIAS NOS ANOS INICIAIS DO ENSINO FUNDAMENTAL: UMA PROPOSTA DIDÁTICA COM A TEMÁTICA VÍRUS
}

\author{
SCIENCE EDUCATION IN THE FIRST YEARS OF FUNDAMENTAL EDUCATION: \\ A TEACHING PROPOSAL ON THE VIRUS TOPIC
}

\author{
ALBERTO LOPO MONTALVÃO NETO 1 \\ LOURDES APARECIDA DELLA JUSTINA²
}

\section{RESUMO}

A pandemia da Covid-19 deixa marcas em diversas esferas, estando a educação entre elas. Outrossim, as questões sociocientíficas sobre a temática vírus tomam centralidade nas mídias e nas pesquisas acadêmicas. Destarte, neste estudo tecemos algumas reflexões. Num primeiro momento, apresentamos uma revisão de literatura, numa abordagem exploratória e bibliográfica. Com base nos resultados encontrados, apresentamos uma proposta de ensino voltada ao $4^{0}$ ano do ensino fundamental, num trabalho interdisciplinar, pautado na perspectiva CTS. Assim, abordamos alguns aspectos preventivos, bem como questões sociopolíticas que envolvem o tema. Os resultados indicam uma carência de pesquisas sobre o tema vírus nos anos iniciais do ensino fundamental. Ademais, a Sequência Didática proposta nos parece uma possibilidade para integrar distintos saberes. Concluímos que se fazem necessárias outras abordagens sobre o tema que possibilitem a assunção de posicionamentos perante questões científicas e tecnológicas, em contextos pandêmicos e pós-pandêmicos.

Palavras-chave: Ensino de Ciências. Vírus. Sequência Didática. Anos Iniciais do Ensino Fundamental.

\section{ABSTRACT}

The Covid-19 pandemic leaves its mark on several spheres, such as administration and education among them. In short, the socio-scientific questions about a virus topic, going to focus in the social media and in academic research. Thus, in this study we make some reflections. First, we present a review of the literature, in an exploratory and bibliographic approach. Based on the results found, we present a teaching proposal aimed at the 4th year of elementary school, in an interdisciplinary work, based on the STS perspective. Thus, we address some preventive aspects, as well as the socio-political issues surrounding the topic. The results indicate a lack of research on the topic of viruses in the early years of elementary school. Furthermore, the proposed didactic sequence seems to us to be a possibility to integrate different types of knowledge. We conclude that other approaches on the topic are necessary to enable the assumption of positions regarding scientific and technological issues, in pandemic and post-pandemic contexts.

Keywords: Science teaching. Virus. Didactic Sequence. Early Years of Elementary School.

\section{RESUMEN}

La pandemia por el Covid-19 deja su huella en varios ámbitos, entre ellos la educación. Así, las cuestiones sociocientíficas sobre la temática virus se vuelven central en los medios y en la investigación académica. Entónces, en este estudio, haremos algunas reflexiones. Primeramente, presentamos una revisión de la literatura, en un enfoque exploratorio y bibliográfico. Con base en los resultados encontrados, presentamos una propuesta didáctica dirigida al

1 Doutorando em Educação pela Universidade Estadual de Campinas (UNICAMP). Bolsista CNPq. E-mail: montalvaoalberto@gmail.com. ORCID: https://orcid.org/0000-0002-4875-646X.

2 Doutora em Educação para a Ciência pela Universidade Estadual Paulista Júlio de Mesquita Filho (UNESP). Professora Associada da Universidade Estadual do Oeste do Paraná (UNIOESTE). E-mail: Iourdesjustina@gmail.com. ORCID: https://orcid.org/0000-0001-6013-7234. 
$4^{0}$ año de la escuela primaria, en un trabajo interdisciplinario, basado en la perspectiva CTS. Así, abordamos algunos aspectos preventivos y las cuestiones sociopolíticas que rodean el tema. Los resultados indican una falta de investigación sobre el tema del virus en los primeros años de la escuela primaria. Además, la secuencia didáctica propuesta nos parece una posibilidad para integrar diferentes tipos de conocimientos. Concluimos que otros enfoques sobre el tema son necesarios para permitir la asunción de posiciones sobre cuestiones científicas y tecnológicas, en contextos pandémicos y pospandémicos.

Palabras-clave: Enseñanza de las ciencias. Virus. Secuencia didáctica. Primeros años de la escuela primaria.

\section{INTRODUÇÃO}

Parece indiscutível que desde 0 início do ano de 2020 vivenciamos um cenário marcado como um dos mais desafiadores e complexos que tivemos neste século XX|3. Isso porque, para além de crises econômicas e políticas que vivenciávamos no Brasil e no mundo até então, também tivemos a insurgência de uma crise, que não apenas é sanitária como também social. Isso porque esse momento histórico, marcado pela pandemia da Covid-19, se colocou como um fator agravante para vários problemas socioeconômicos e políticos já existentes, ceifando milhares de vidas no Brasil e outras milhões no mundo (WERNECK; CARVALHO, 2020, MONTALVÃ0 et al., 2021, entre outros).

Comparada a outros episódios históricos do século passado, tais como os surtos de varíola que ocorreram no início do século XIX; a gripe espanhola, que ocorre logo após a Primeira Guerra Mundial (1918); 0 surto de sarampo, que causou a morte de muitos infantes nos anos 1960 (FONSECA; FRANCO, 2020); e as altas taxas de infecção pela síndrome da imunodeficiência adquirida (HIV) nos anos 1980; a crise sanitária e social ocasionada pelo novo coronavírus nos colocou sob a égide de novos desafios de saúde pública e levou diversas nações à medidas de distanciamento social. Consequentemente, essa crise nos levou também à emergência de novas práticas e de outras formas de agir e interagir com as pessoas em nossas atividades cotidianas.

Destarte, considerando que a temática vírus se coloca como uma questão de destaque no atual cenário mundial, em diferentes âmbitos, e que os vírus são organismos de interesse no ensino de Ciências/Biologia, principalmente na relação existente entre Ciência, Tecnologia e Sociedade (CTS) no presente texto trazemos algumas reflexões que consideramos relevantes sobre as questões sociocientíficas ${ }^{4}$ e que envolvem a temática em questão. De acordo com Santos e Mortimer (2002, p. 1), um currículo de ensino de Ciências que se pauta em pressupostos CTS, movimento que ocorre desde a década de 1960, tem como intuito principal "[...] preparar os alunos para o exercício da cidadania e caracterizam-se por uma abordagem dos conteúdos científicos no seu contexto social". É a partir dessa concepção que discutiremos essa relação entre Ciência, Tecnologia e Sociedade. Para tal, nos filiamos ao âmbito educacional, ao trazermos uma proposta de ensino, e à pesquisa em educação em Ciências, ao buscarmos compreender como essa temática vem sendo tratada na área.

Entre as questões que justificam o interesse desta pesquisa está o próprio conhecimento que temos a respeito dos vírus. Isso porque, apesar da ampla divulgação pela mídia de diversos aspectos sobre a temática desde 0 início da pandemia, muitas são as questões que envolvem a Biologia

30 presente estudo teve a sua escrita finalizada no primeiro semestre de 2021.

4 De acordo com Silva e Ferreira (2021, p. 30), as questões sociocientíficas podem "[...] propiciar e potencializar aproximações educativas que intencionam e direcionam para problematização, organização, articulação e aplicação de conhecimentos cotidianos e científicos que manifestam-se na sociedade". Em outras palavras, podemos dizer que são questões controversas e atuais, que relacionam aspectos sociais, científicos e tecnológicos, sendo essas questões pauta de discussão em diferentes âmbitos e contextos. 
viral, visto que, ainda hoje, há controvérsias a respeito de os vírus serem considerados ou não como seres vivos. Entre outras questões, podemos apontar que os vírus são considerados como parasitas intracelulares obrigatórios e, portanto, não possuem estruturas celulares básicas, nem são capazes de sobreviver e se desenvolver sem utilizar de outros seres vivos para este fim. Há, então, uma controvérsia científica, que torna a compreensão dos vírus um desafio para a própria Ciência. Nesse cenário, Stephens et al. (2009) afirmam que há especialistas que não consideram os vírus como organismos vivos, dadas as características parasitárias descritas, e há aqueles que consideram que estes organismos são seres vivos, pelo fato deles realizarem funções e possuírem estruturas básicas similares a de outros organismos, como, por exemplo, a capacidade de se replicar e a presença de material genético.

Para além dos aspectos biologicamente controversos, temos no atual cenário pandêmico a intensificação de controvérsias geradas a partir de notícias falaciosas a respeito do novo coronavírus. Nesse viés, vemos que atualmente diversas fake news ${ }^{5}$ têm sido compartilhadas pelas redes sociais e frequentemente causam uma série de consequências à população. Um exemplo disso é a crença em notícias que levam à descrença da eficácia da vacina ao enfrentamento da Covid-19, bem como a propagação de informações falsas a respeito de métodos preventivos à doença (MONTALVÃO NETO et al., 2020). Assim, os impactos mencionados são resultantes do "[...] desconhecimento e do medo da população de novas tecnologias [...]", ou pelo "[...] receio de antigas tecnologias como as vacinas, aliado a falta de senso crítico em diferenciar uma notícia falsa de uma verdadeira" (KARAT; BUSKO; GIRALDI, 2019, p. 123). Ademais, cabe pontuar que, tal como apontam Montalvão Neto et al. (2020), a recente democratização da informação, proporcionada pelos meios digitais, não apenas ampliou a circulação/popularização de conteúdos fidedignos, como também disseminou notícias falsas, levando à dualidade contemporânea mencionada.

Com base nas afirmações supramencionadas, considera-se como igualmente importante pensar a aprendizagem científica e tecnológica como algo a ser trabalhado desde os primeiros anos do ensino fundamental, de modo a abrir margens para que se possa construir com diferentes conhecimentos para com os estudantes, conhecimentos esses que vão para além dos conceitos científicos e englobam aspectos sociais, éticos, políticos, econômicos, ambientais, de saúde, entre outros. Essa abrangência de conteúdos socialmente relevantes, ou também chamados de sociocientíficos (MONTALVÃO NETO, 2016), visa proporcionar, então, a possibilidade de que os sujeitos recebam informações sobre temas científicos e tecnológicos, estreitando ainda a relação desses conhecimentos com questões que sejam de interesse de diversos setores da sociedade. Em outras palavras, busca-se possibilitar o desenvolvimento destes sujeitos para que possam refletir, posicionarem-se e debaterem criticamente as questões cotidianas (SASSERON; CARVALHO, 2008).

Considerando as questões mencionadas, no presente trabalho temos como intuito responder ao seguinte problema de pesquisa: De que maneira a pesquisa em Educação em Ciências (pode) colabora(r) para a construção de aprendizagens, sociais e científicas, e para a compreensão de diferentes aspectos relacionados à temática vírus e à pandemia da Covid-19? Assim, o objetivo deste estudo é compreender a produção acadêmica a respeito da temática vírus, de forma a possibilitar a elaboração de estratégias e propostas de ensino que contribuam significativamente com a aprendizagem científica em meio a contextos pandêmicos.

5 Diferentes notícias e estudos têm sido divulgados a respeito das fake news que circularam por vários veículos de informação/comunicação desde 0 início da pandemia da Covid-19. Entre os canais de informação que buscam combater notícias falaciosas podemos mencionar a plataforma on-line da Fundação Oswaldo Cruz (FIOCRUZ). Disponível em: https://portal.fiocruz.br/noticia/estudo-identifica-principais-fake-news-relacionadas-covid-19. Acesso em: 23 dez. 2020. 
Destarte, visando atingir o objetivo anunciado e responder à questão de pesquisa, visamos: a) Compreender alguns padrões sobre a produção acadêmica em ensino de Ciências sobre a temática vírus, a partir de uma breve revisão bibliográfica; b) Analisar os principais resultados das pesquisas em Educação em Ciências sobre a temática de interesse, considerando as potencialidades, os desafios e as lacunas por elas apontadas; c) Propor uma Sequência Didática (SD) sobre o tema vírus, considerando os principais aspectos sociocientíficos que 0 envolvem, a partir das lacunas encontradas na análise de nosso corpus.

\section{ASPECTOS METODOLÓGICOS DA PESQUISA}

Como dissemos, num primeiro momento, para responder à questão pergunta da pesquisa, como recorte, investigamos alguns aspectos referentes à recente produção acadêmica a respeito do tema, a partir de um breve levantamento bibliográfico sobre a temática vírus nas atas do Encontro Nacional de Pesquisa em Educação em Ciências (ENPEC) ${ }^{6}$. Trata-se de um evento voltado à divulgação de pesquisas em Educação em Ciências Naturais (Biologia, Química, Física e Geociências) e em Educação Matemática, agregando estudos de diferentes níveis de ensino, elaborados por pesquisadores oriundos de diversas instituições e que possuem distintas perspectivas teóricas e/ou empíricas.

Com base na pergunta e nos objetivos de pesquisa, o presente trabalho caracterizou-se, metodologicamente, como uma pesquisa mista, de natureza qualitativa e quantitativa, a qual podemos enquadrar como um estudo do tipo exploratório e bibliográfico (GIL, 2008). Assim, apresentamos alguns resultados quantitativos, por meio de tabelas, ao passo que também realizamos algumas breves discussões a respeito desses resultados. Buscando refletir sobre as implicações desses resultados para a área, essas discussões serão delineadas de forma descritiva-interpretativa.

A revisão bibliográfica foi feita a partir de buscas em todas as edições do Encontro Nacional de Pesquisa em Educação em Ciências (ENPEC). Ao todo foram revisadas 12 edições do evento, visto que ele ocorre com periodicidade bianual desde 0 ano de 1997. Para a busca foi utilizada a palavra-chave "vírus", a qual buscamos nos títulos, resumos e/ou palavras-chaves desses trabalhos. Para isso, utilizamos os mecanismos de busca que estão disponíveis nas próprias plataformas que congregam as atas do evento, sendo isso feito sempre que essa opção estava disponível. No entanto, em algumas versões mais antigas das atas do ENPEC, a busca teve de ser feita de modo manual, lendo texto a texto, visto que não havia ferramentas de busca disponíveis. Cabe salientar ainda que não foi possível realizar buscas nas atas referente ao ano de 2009, pois o site se encontrava indisponível.

Para a análise dos dados obtidos a partir da revisão de literatura levou-se em consideração os seguintes descritores: a) ano de publicação; b) título dos trabalhos; c) autores; d) instituição e regionalidade; e) principais enfoques de pesquisa - tema central, abordagens e/ou metodologia(s) do estudo. A partir desses descritores, elaboramos as tabelas 1 e 2, apresentadas na próxima seção.

Acreditamos que, desse modo, com 0 uso desses descritores, foi possível caracterizar alguns aspectos sobre a produção acadêmica a respeito do tema de interesse: vírus. Com esse mapeamento compreendemos algumas lacunas sobre a questão, as quais apresentaremos a seguir. Todavia, cabe salientar que, com base nas lacunas identificadas a partir da revisão de literatura, chegamos à proposição de uma SD que visa contemplar algumas lacunas educacionais por nós identificadas. Destarte, por SD compreendemos "[...] um conjunto de atividades ordenadas, estruturadas e articuladas para 6 Disponível em: http://abrapecnet.org.br/wordpress/pt/enpecs-anteriores/. Acesso em: 27 dez. 2020. 
a realização de certos objetivos educacionais, que têm um princípio e um fim conhecidos tanto pelos professores como pelos alunos" (ZABALA, 1998, p. 18).

A SD em questão pautou-se nos pressupostos de ensino dispostos na Base Nacional Comum Curricular - BNCC (BRASIL, 2018). 0 trabalho relativo à aprendizagem em Ciências, desde os anos iniciais de ensino, está contemplado em diferentes documentos curriculares nacionais, estando entre as orientações mais recentes as indicações apontadas pela BNCC. Esse documento, vigente desde 0 ano de 2017, indica a necessidade de que sejam trabalhadas determinadas habilidades e competências na educação básica, que se relacionam ao cuidado do corpo (de si) e à saúde da criança. Assim, como será mostrado adiante, a construção da proposta de ensino aqui apresentada orienta-se com base em competências e habilidades propostas por este documento e pauta-se em um viés de interdisciplinaridade.

\section{REVISÃO DE LITERATURA: A TEMÁTICA VÍRUS NAS PESQUISAS EM ENSINO DE CIÊNCIAS}

A seguir, apresentamos na tabela 10 número de trabalhos encontrados anualmente, a respeito da temática vírus, nas pesquisas publicadas no ENPEC.

Tabela 1 - Número de pesquisas sobre vírus publicadas no ENPEC.

\begin{tabular}{cccccccccccc}
\hline 1997 & 1999 & 2001 & 2003 & 2005 & 2007 & 2009 & 2011 & 2013 & 2015 & 2017 & 2019 \\
\hline 0 & 0 & 0 & 0 & 2 & 0 & - & 3 & 0 & 0 & 1 & 1 \\
\hline \multicolumn{1}{c}{ Fonte: autoria própria. } & & &
\end{tabular}

Pela tabela 1, podemos notar que em muitas edições do evento não houve publicações referentes ao tema vírus. Apenas nos anos de 2005, 2011, 2017 e 2019 foram encontrados trabalhos com esse enfoque temático, sendo 0 ano de 2011 aquele em que teve um maior número de publicações no ENPEC (3).

Ao todo foram encontrados sete trabalhos com a palavra-chave de interesse. Para compreendermos melhor quais foram os tipos de estudos publicados no evento sobre o tema vírus, na tabela 2, apresentada a seguir, trazemos alguns elementos, descrições e ponderações de especificidades a esse respeito, considerando os descritores anteriormente mencionados.

Tabela 2 - Descrição dos trabalhos encontrados na revisão de literatura.

\begin{tabular}{|c|c|c|c|c|c|}
\hline $\mathrm{N}^{0}$ & Ano & Título & Autores & Instituição & Foco \\
\hline $\mathrm{T}-1$ & 2005 & $\begin{array}{l}\text { Prevenção à dengue na escola: } \\
\text { concepções de alunos do } \\
\text { ensino médio e considerações } \\
\text { sobre vias de informação. }\end{array}$ & $\begin{array}{l}\text { Izabel C. N. de Araújo; } \\
\text { Tania C. de Araújo-Jorge; } \\
\text { Rosane M. S. de Meirelles }\end{array}$ & Fiocruz / RJ & $\begin{array}{l}\text { Apropriação de informações midiáticas } \\
\text { sobre o tema dengue por alunos de ensino } \\
\text { médio. Análise de Conteúdo de questioná- } \\
\text { rios semiestruturados para compreender } \\
\text { concepções de estudantes. }\end{array}$ \\
\hline T-2 & 2005 & $\begin{array}{l}\text { A prática da interdisciplina- } \\
\text { ridade em sala de aula: um } \\
\text { estudo exploratório, utilizando } \\
\text { vírus como modelo }\end{array}$ & $\begin{array}{l}\text { Elisabete F. C. Schmidt; } \\
\text { Paula C. Fonseca; Luiz A. } \\
\text { Alves }\end{array}$ & Fiocruz / RJ & $\begin{array}{l}\text { Proposta interdisciplinar sobre o tema } \\
\text { vírus para o ensino médio, com análise de } \\
\text { dados por teste estatístico. }\end{array}$ \\
\hline
\end{tabular}

vírus como modelo 


\begin{tabular}{|c|c|c|c|c|c|}
\hline T-3 & 2011 & $\begin{array}{l}\text { Educação sexual: as relações } \\
\text { entre conhecimentos, valores e } \\
\text { práticas sociais de prevenção } \\
\text { da disseminação do vírus HIV }\end{array}$ & $\begin{array}{l}\text { Patrícia da S. Nunes; } \\
\text { Paloma R. da Silva; Osmar } \\
\text { Cavassan; Ana Maria A. } \\
\text { Caldeira }\end{array}$ & UNESP & $\begin{array}{l}\text { Compreensão das concepções de alunos } \\
\text { do ensino médio sobre a transmissão e } \\
\text { prevenção do HIV por meio de análise } \\
\text { qualitativa e estatística. }\end{array}$ \\
\hline T-4 & 2011 & $\begin{array}{l}\text { Concepções espontâneas } \\
\text { sobre vírus dos alunos do } 6^{0} \\
\text { ao } 9^{\circ} \text { ano }\end{array}$ & $\begin{array}{l}\text { Paula B. Oliveros; Mariana } \\
\text { L. da Silveira; Magnólia } \\
\text { Araújo }\end{array}$ & UFRN & $\begin{array}{l}\text { Análise de Conteúdo de concepções espon- } \\
\text { tâneas de alunos do ensino fundamental II } \\
\text { sobre o tema vírus. }\end{array}$ \\
\hline T-5 & 2011 & $\begin{array}{l}\text { Dengue: reflexões acerca } \\
\text { da incidência da doença em } \\
\text { estado do nordeste brasileiro } \\
\text { sobre o tema em livros didáti- } \\
\text { cos de ciências }\end{array}$ & $\begin{array}{l}\text { Waleska I. T. dos S. } \\
\text { Barros; Rodrigo L. Lima; } \\
\text { Marcia G. L. da Silva; } \\
\text { Elinei A. de Almeida }\end{array}$ & UFRN & $\begin{array}{l}\text { Análise qualitativa de livro didático do } 7^{\circ} \\
\text { ano do Ensino Fundamental sobre o tema } \\
\text { "Dengue". }\end{array}$ \\
\hline T-6 & 2017 & $\begin{array}{l}\text { Vírus e modelagem para a } \\
\text { Educação em Saúde: uma } \\
\text { investigação no Parque da Ci- } \\
\text { ência/Museu da Vida/Fiocruz }\end{array}$ & $\begin{array}{l}\text { Camylla A. M. de Oliveira, } \\
\text { Maria Paula de 0. Bonatto }\end{array}$ & $\begin{array}{l}\text { UFRJ / Museu da } \\
\text { Vida / Fiocruz }\end{array}$ & $\begin{array}{l}\text { Relato de experiência: oficina com mo- } \\
\text { delagem de microrganismos - educação } \\
\text { em espaço não-formal; análise reflexiva, } \\
\text { com base em formulário de observação - } \\
\text { registro de reações dos visitantes. }\end{array}$ \\
\hline T-7 & 2019 & $\begin{array}{l}\text { Mundo unicelular: descobrindo } \\
\text { a modelagem para abordar pro- } \\
\text { porções microscópicas e saúde } \\
\text { no museu da vida/Fiocruz }\end{array}$ & $\begin{array}{l}\text { Lucas H. Lopes; Paulo S. } \\
\text { C. Henrique; Julia S. Pinto; } \\
\text { Maria Paula O. Bonatto; } \\
\text { Paulo H. Colonese }\end{array}$ & $\begin{array}{l}\text { Museu da Vida / } \\
\text { C.U. Celso Lisboa } \\
\text { / Fiocruz / UFRJ }\end{array}$ & $\begin{array}{l}\text { Relato de experiência: modelagem de } \\
\text { seres microscópicos para o ensino de } \\
\text { microbiologia - educação em espaço } \\
\text { não-formal de ensino (museu). }\end{array}$ \\
\hline
\end{tabular}

\section{Fonte: autoria própria.}

Com base nos resultados apresentados na Tabela 2, podemos observar que houve uma certa predominância de trabalhos sobre a temática vírus. Esses trabalhos foram realizados por pesquisadores que atuam em instituições localizadas principalmente na região sudeste e, mais especificamente, em instituições do estado do Rio de Janeiro (T-1; T-2, T-6, T-7). Em especial, observamos que esses pesquisadores estão vinculados, principalmente, à Fundação Oswaldo Cruz (Fiocruz), uma das principais instituições da América Latina entre as que atuam na promoção e difusão de questões científicas e tecnológicas voltadas à saúde, e atuando, portanto, como um agente da cidadania?. Esses trabalhos foram realizados, portanto, por pesquisadores da saúde, que buscam pensar em ações preventivas a serem abordadas na educação científica, em perspectivas de ensino formal e/ou informal.

Sobre os principais objetos das pesquisas encontradas na revisão bibliográfica sobre o tema vírus, podemos observar que os estudos se debruçam sobre a: a) compreensão de concepções de alunos a respeito da temática vírus, principalmente por meio de questionários ou por intermédio de outros instrumentos de coleta/observação (T-3; T-4); b) análise de materiais didáticos escolares (T-5); c) propostas didáticas e relatos de experiência sobre o tema em questão (T-1; T-2; T-6; T-7). Nota-se que as pesquisas que se voltam a essas propostas educacionais coadunam com os resultados supramencionados, visto que seus autores pertencem à área da saúde, trabalhando na Fiocruz. Assim, observamos que as principais propostas de ensino apresentadas por esses trabalhos provêm de profissionais da saúde, que realizam as suas pesquisas deslocando-se até a escola ou indo a espaços não-formais, tais como os museus. Desse modo, observamos que há uma escassez de pesquisas que tragam proposições didáticas elaboradas diretamente por/para educadores que atuam no ensino de Ciências, se fazendo necessário, portanto, que se pense em propostas capazes de trazer possibilidades aos professores de Biologia/Ciências para trabalhar questões a respeito da temática, numa perspectiva de Educação em saúde.

Diante dessa questão, cabe ressaltar algumas distinções entre os termos "Educação em saúde" e "Educação na saúde". De acordo com Falkenberg et al. (2014), a "Educação em saúde" envolve

\footnotetext{
7 Essas informações foram extraídas diretamente da página da Fiocruz. Disponível em: https://portal.fiocruz.br/fundacao. Acesso em: 28 dez. 2020.
} 
diferentes profissionais e tem como objetivo principal a intenção de que a população se aproprie de conhecimentos relacionados à saúde, de forma crítica e reflexiva, visando assim que os sujeitos possam posicionar-se perante as questões sociais, cidadãs, científicas e tecnológicas. Quando se trata da educação de/por profissionais da saúde, com enfoque na promoção e conscientização dessas questões, temos, então, a "Educação na saúde". Neste sentido, consideramos que os trabalhos encontrados, que fizeram pesquisas em educação de caráter empírico pautados em propostas didáticas, em sua maioria, enquadravam-se neste segundo tipo de abordagem.

Pensando nesses aspectos, especificamente em relação ao ensino de Ciências, podemos dizer que 0 termo "Educação em saúde" pode ser utilizado para "[...] designar as atividades realizadas como parte do currículo escolar, que tenham uma intenção pedagógica definida, relacionada ao ensino-aprendizagem de algum assunto ou tema relacionado com a saúde individual ou coletiva" (MOHR, 2002, p. 38). Assim, de acordo com Mohr (2002), no ensino de Ciências, a Educação em saúde parte do pressuposto de que 0 ensino ali praticado é intencional, planejado e que visa ensinar algo a alguém, tomando-a, assim, parte integrante do currículo e como algo a ser desenvolvido por profissionais da educação. Esse desenvolvimento por sua vez pode ser feito em parceria com outros profissionais, principalmente aqueles relacionados à saúde. Por isso, consideramos de suma importância que a Educação em saúde seja pensada no âmbito escolar, ou seja, por professores e pesquisadores do ensino de Ciências, não restringindo-se a profissionais da saúde, mas sim sendo pauta de educadores e dos currículos.

A respeito das principais abordagens metodológicas para a análise de dados, observamos que duas pesquisas se utilizaram da Análise de Conteúdo (T-1; T-4); outras duas se utilizaram de testes estatísticos (T-2; T-3); e quatro estudos se utilizaram de abordagens qualitativas, do tipo descritiva-interpretativa ou reflexiva, para a compreensão dos dados (T-3; T-5; T-6; T-7). Nota-se, portanto, que houve uma predominância de pesquisas qualitativas.

Em relação aos níveis de ensino aos quais essas pesquisas se voltam, observamos que duas delas referem-se a espaços não-formais (museus) (T-6; T-7); três se direcionaram a compreensões de questões do ensino médio (T-1; T-2; T-3); e duas pesquisas relacionam-se aos anos finais do ensino fundamental (T-4; T-5). Nenhuma pesquisa, relacionada aos anos iniciais do ensino fundamental, foi encontrada. Isso corrobora nossas pretensões iniciais, apontando para a importância da realização de pesquisas em Educação em Ciências, neste nível de ensino, voltadas à temática vírus.

Considerando que a aprendizagem de questões científicas deve ser incentivada desde os anos iniciais de estudo, de forma a garantir que os alunos possam, desde cedo, aprender a refletir criticamente sobre contextos cotidianos e a se posicionarem perante questões científicas e tecnológicas (SASSERON; CARVALHO, 2008), e considerando ainda que os cuidados com o corpo e com a saúde pessoal integram os atuais componentes curriculares (BRASIL, 2018), reafirmamos que há uma carência de pesquisas sobre a temática vírus na pesquisa e no ensino de Ciências. Assim, acreditamos que é de grande relevância a proposição de abordagens que se remetam à compreensão dos vírus, em seus aspectos científicos, sociais e aos possíveis cuidados de higiene preventivos, principalmente em meio ao atual contexto pandêmico.

A respeito das questões relacionadas à prevenção, abordagens que trabalhem com esse objetivo se tornam importantes na medida em que, não apenas auxiliam em situações de crise sanitária, como a ocasionada pela disseminação do vírus da Covid-19, como também colabora para que medidas de controle epidêmicas (e pandêmicas) se tornem habituais, mesmo após o fim dessa crise (ARAÚJO; ARAÚJO-JORGE; MEIRELLES, 2005). Além disso, adotando hábito preventivos é possível fomentar a 
participação cidadã em relação às questões de saúde, principalmente aquelas que envolvam as esferas científicas, políticas, sociais, ambientais e de saúde pública (OLIVEIRA; BONATTO, 2017). Acreditamos que assim é possível fomentar não apenas o conhecimento biológico sobre organismos microscópicos como os vírus, como também abordar-se-á distintos aspectos sociocientíficos.

Com base nessas ponderações, a seguir, relatamos os contextos de elaboração de uma SD, desenvolvida com foco em um trabalho sobre a temática vírus nos anos iniciais do ensino fundamental. Essa proposta foi criada ao longo do desenvolvimento de um Trabalho de Conclusão de Curso (TCC), elaborado pelo primeiro autor deste trabalho para a obtenção do título de Licenciado em Pedagogia. 0 título foi obtido como uma segunda licenciatura do pesquisador, que tem como primeira formação o título de Licenciado em Ciências Biológicas. Ademais, atualmente o pesquisador realiza a sua pesquisa de doutorado voltando-se às questões do ensino de Ciências. Assim, aliando diferentes experiências, o TCC mencionado derivou, principalmente, das proposições de atividades pelo primeiro autor deste manuscrito em seu relatório de Estágio Supervisionado, elaborado nos moldes de Ensino Remoto Emergencial. Destarte, a SD apresentada deriva de bases teóricas e empíricas, experenciadas por este autor, que culminaram em sua proposição.

\section{UMA PROPOSTA DIDÁTICA SOBRE O TEMA VÍRUS}

Para a elaboração de uma SD consideramos que é de fundamental importância termos conhecimento da composição do currículo a ser seguido. Nesse sentido, Barbiero, Santos e Albano (2020, p. 581) ressaltam que, "[...] para direcionar o trabalho pedagógico, é necessária uma proposta curricular fundamentada nos princípios de formação humana, pautada nos conhecimentos científicos historicamente acumulados pela humanidade". Nessa perspectiva, consideramos que os documentos curriculares comumente trazem como pauta à necessidade de uma formação cidadã, pautada em pressupostos humanizadores e que leve os alunos a reflexões críticas sobre o mundo que os cercam. Por isso, pautamos a construção dessa proposta de ensino no documento curricular vigente, orientador das práticas escolas na atualidade.

Entre os documentos curriculares mais recentes está a BNCC. Em conformidade com 0 Plano Nacional de Educação (PNE) e com a Lei de Diretrizes e Bases da Educação Nacional (LDB), a BNCC surge como 0 intuito de atender às demandas educacionais que estão em voga de discussões adjacentes à Constituição Federal de 1988. Assim, este documento é "[...] orientado pelos princípios éticos, políticos e estéticos que visam à formação humana integral e à construção de uma sociedade justa, democrática e inclusiva (DCN) (BRASIL, 2018, p. 7). Ademais, a BNCC "[...] é um documento de caráter normativo que define o conjunto orgânico e progressivo de aprendizagens essenciais que todos os alunos devem desenvolver ao longo das etapas e modalidades da Educação Básica" (BRASIL, 2018, p. 7).

Todavia, cabe ressaltar que, apesar dos pressupostos humanizadores que balizam as orientações descritas na BNCC, há questões controversas em seu processo de formulação e aprovação, dadas as mudanças que ocorreram no documento em decorrência de questões políticas / mudanças governamentais (NASCIMENTO et al., 2019). Nascimento e colaboradores (2019) apontam que, apesar da suma importância que este documento curricular assume na educação, principalmente no que se refere ao ensino de Ciências, há mudanças significativas entre a $2^{\mathrm{a}}$ e $3^{\mathrm{a}}$ versão da base, sendo esta última a versão aprovada. Como consequência houve a supressão de vieses educacionais críticos, que vinham sendo apontados como importantes por pesquisadores da área. 
Entretanto, consideramos que, sendo este 0 documento vigente e que orienta os currículos e as práticas educacionais na atualidade, se faz necessário considerá-lo na proposição de atividades de ensino. Por isso, nossa proposta de ensino se baseia nas competências e habilidades expostas neste documento orientador, em que, entre as dez competências gerais estabelecidas na BNCC, está a valorização de conhecimentos de diversos campos do saber (histórico, artístico, socioemocionais, científicos, tecnológicos, matemático, linguísticos, entre outros), além da indicação de que se faz necessário o desenvolvimento de habilidades reflexivas, analíticas, investigativas, criativas, comunicacionais, relacionadas autocuidado/autoconhecimento e que levem à tomada de posições/decisões por parte dos alunos (BRASIL, 2018).

Pensando nesses vieses de criticidade, a proposta de ensino apresentada teve como pressupostos básicos alguns dos diferentes objetivos de aprendizagem propostos pela BNCC. Todavia, temos como principal foco um trabalho que se volte à temática vírus no $4^{\circ}$ ano do ensino fundamental, visto que, entre as principais orientações para este nível de ensino, o documento aponta que devemos "(EF04CI08) Propor, a partir do conhecimento das formas de transmissão de alguns microrganismos (vírus, bactérias e protozoários), atitudes e medidas adequadas para prevenção de doenças a eles associadas" (BRASIL, 2018).

Consideramos que o objetivo de aprendizagem supramencionado, voltado ao ensino de Ciências nos anos iniciais do ensino fundamental, atrela-se a uma perspectiva interdisciplinar de ensino, visto que, além dos conteúdos de (micro)biologia envolvidos com a questão, poderíamos considerar algumas relações com outros campos disciplinares, principalmente ao tratarmos sobre os processos de propagação do vírus, além dos atos preventivos e impactos socioeconômicos, políticos e no bem-estar social, como ocorre atualmente na pandemia da Covid-19. Isso se torna ainda mais evidente se levarmos em conta outros objetivos de aprendizagem expostos na BNCC, relativos a outras áreas do conhecimento, tais como português, história, geografia, matemática etc. Isso porque, consideramos que, ao olharmos para um acontecimento de amplas implicações, como, por exemplo, a propagação do novo coronavírus, a partir da ótica desses saberes, poder-se-á compreender os mecanismos pelos quais essa crise, social e sanitária, afeta diferentemente as pessoas, em distintos contextos e âmbitos locais e/ou globais.

Destarte, as orientações curriculares da BNCC coadunam com uma perspectiva de ensino que visa educar para a promoção da saúde e que converge com as orientações promulgadas por diversas organizações mundiais para o enfrentamento à pandemia da Covid-19, como, por exemplo, a Organização Mundial da Saúde (OMS), que, assim como outras organizações, orientam para diferentes medidas de prevenção à doença, como, por exemplo, a prática de hábitos de higienização e de distanciamento sociali .

Dessa maneira, nos propomos a abordar a temática vírus sob diferentes aspectos, considerando, inclusive, questões relacionadas à perspectiva de Educação em saúde. Assim, ao trabalharmos com uma perspectiva que visa uma educação pautada em aspectos de prevenção e de enfrentamento a doenças, tais como o novo coronavírus, consideramos, inclusive, o quão abstrato esse conteúdo pode parecer perante grande parte da população, principalmente dado ao seu caráter microscópico. Nesse sentido, julgamos essa abordagem necessária por assumirmos que:

A educação em saúde, em suas interfaces com as ciências biológicas, envolve uma série de abstrações sobre os seres vivos invisíveis a olho nu, de dimensões da ordem de micrômetros a nanômetros, contudo, 0 acesso a instrumentos que permitem essa visualização não é popularizado. A questão está na dificuldade de tornar

8 Disponível em: https://sbpt.org.br/portal/covid-19-oms/. Acesso em: 23 nov. 2020. 
interessante e palpável a aprendizagem daquilo que não se vê, sobrepujando imagens gráficas bidimensionais (LOPES et al., 2019, p. 2).

Nesse sentido, as atividades aqui descritas como propostas interventivas, potenciais de serem utilizadas em sala de aula, buscam superar algumas dessas dificuldades abstrativas, por meio de uma mobilização de diferentes conhecimentos e práticas, que permitem ao aluno se (in)formar a respeito do tema, através de múltiplas visões a respeito do tema em questão.

Desse modo, assumindo como premissa a necessidade de elaboração de abordagens que deem visibilidade, principalmente por meios lúdicos, àquilo que não podemos ver, como é o caso dos vírus, a tabela 3, a seguir, apresenta sucintamente a proposta de ensino que elaboramos para tal finalidade.

Tabela 3 - Proposta didática sobre a pandemia da Covid-19.

\begin{tabular}{|c|c|c|c|c|}
\hline N & Título & Objetivos de aprendizagem & Hab. BNCC & Descrição \\
\hline 1 & 0 que é um vírus? & $\begin{array}{l}\text { a) Compreender concepções prévias } \\
\text { sobre os vírus; b) Refletir sobre a } \\
\text { polissemia da palavra; c) Identificar as } \\
\text { principais características de um vírus. }\end{array}$ & $\begin{array}{c}\text { EF04LP03 } \\
\text { EF04LP21EF04LP20 } \\
\text { EF04LP24 } \\
\text { EF04MA27EF04MA28 }\end{array}$ & $\begin{array}{l}\text { 1) Questionamento inicial: o que são os vírus?; 2) } \\
\text { Pesquisa comparativa: vírus biológicos (enfermi- } \\
\text { dades) x virtuais (computadores); 3) Elaboração } \\
\text { de tabela sintetizando os resultados }{ }^{9} \text {. }\end{array}$ \\
\hline 2 & $\begin{array}{l}\text { Qual é a diferença } \\
\text { entre o vírus da } \\
\text { Covid-19 e o de uma } \\
\text { gripe comum? }\end{array}$ & $\begin{array}{l}\text { a) Conhecer a Biologia dos vírus; b) } \\
\text { Compreender as diferenças entre } \\
\text { vírus (gripes/resfriados x Covid-19); } \\
\text { c) Sintetizar informações, planejando/ } \\
\text { executando com ferramentas digitais. }\end{array}$ & EF04CI08 EF12LP06 & $\begin{array}{l}\text { 1) Exibição do vídeo "Gripe e Resfriado"10 do } \\
\text { médico Drauzio Varella; 2) Exibição do vídeo } \\
\text { "COVID-19"11 do biólogo e influencer digital Átila la- } \\
\text { marino; 3) Elaboração de vídeo pelos alunos sobre } \\
\text { a diferença entre os tipos de vírus (coronavírus x } \\
\text { gripe comum). }\end{array}$ \\
\hline 3 & $\begin{array}{l}0 \text { que dizem as } \\
\text { diferentes fontes de } \\
\text { informação sobre os } \\
\text { vírus? }\end{array}$ & $\begin{array}{l}\text { a) Identificar a diferença na forma de } \\
\text { diferentes tipos textuais; b) Buscar } \\
\text { informações a partir de diferentes } \\
\text { fontes; c) Elaborar produções textuais } \\
\text { informativas, a partir de narrativas } \\
\text { pessoais. }\end{array}$ & $\begin{array}{l}\text { EF04LP1 EF35LP16 } \\
\text { EF04CI08EF35LP09 }\end{array}$ & $\begin{array}{l}\text { 1) Leituras sobre o novo coronavírus - diferentes } \\
\text { tipos textuais: a) notícia de jornal; b) texto de } \\
\text { divulgação científica; c) artigo científico; d) textos } \\
\text { didáticos; e) manual com técnicas de higienização. } \\
\text { 2) Elaborar notícias de jornal sobre as mudanças } \\
\text { no cotidiano dos alunos durante a pandemia. }\end{array}$ \\
\hline 4 & $\begin{array}{l}\text { Como o vírus se } \\
\text { espalha? }\end{array}$ & $\begin{array}{l}\text { a) Aprender a construir hipóteses e } \\
\text { verificar fatos por meio da experimen- } \\
\text { tação; b) Compreender as formas de } \\
\text { disseminação dos vírus; c) Elaborar } \\
\text { textos de cunho científico (relatório). }\end{array}$ & $\begin{array}{l}\text { EF04CI08 } \\
\text { EF02LP22 } \\
\text { EI03ET02 } \\
\text { EF04LP24 }\end{array}$ & $\begin{array}{l}\text { 1) Atividade lúdica }\left(\text { solutudo }^{12}\right) \text { : as crianças devem } \\
\text { pintar suas mãos com guache e, vendadas, devem } \\
\text { limpá-las, representando a disseminação do vírus. } \\
\text { 2) Atividade com beterraba: as crianças a pegam } \\
\text { com um lenço, de modo a perceberem como } \\
\text { sujam as mãos, algo análogo a assoar o nariz. 3) } \\
\text { Elaboração de relatório científico. }\end{array}$ \\
\hline 5 & $\begin{array}{l}\text { Qual é a importância } \\
\text { de representações } \\
\text { gráficas para com- } \\
\text { preender a Covid-19? }\end{array}$ & $\begin{array}{l}\text { a) Desenvolver o raciocínio lógico } \\
\text { por meio da construção de gráficos; } \\
\text { b) Compreender a importância da } \\
\text { construção de gráficos para o enfren- } \\
\text { tamento da pandemia; c) Aprender a } \\
\text { selecionar e sintetizar dados encontra- } \\
\text { dos por meio de buscas. }\end{array}$ & $\begin{array}{l}\text { EF04LP20 } \\
\text { EF04LP21EF04LP24 } \\
\text { EF04MA28 } \\
\text { EF04CI08 }\end{array}$ & $\begin{array}{l}\text { 1) A importância de gráficos para a compreensão } \\
\text { da Covid-19: vídeo do biólogo Átila lamarino }{ }^{13} \text {. 2) } \\
\text { Construção, pelos alunos, de gráficos simples, } \\
\text { com base nos recentes dados sobre o número } \\
\text { de infectados pela Covid- } 19 \text { no Brasil, a partir de } \\
\text { buscas em sites governamentais e com legendas } \\
\text { explicativas voltadas à prevenção. }\end{array}$ \\
\hline
\end{tabular}

9 Essa atividade foi inspirada no site Nova Escola. Disponível em: https://novaescola.org.br/plano-de-aula/1800/0-que-sao-virus. Acesso em: 29 dez. 2020.

10 Disponível em: https://www.youtube.com/watch?v=SLQZ3Iq_uWU\&ab_channel=DrauzioVarella. Acesso em: 29 dez. 2020.

11 Disponível em: https://www.youtube.com/watch?v=X_HC8aCrHdA\&ab_channel=Atilalamarino. Acesso em: 29 dez. 2020.

12 Disponível em: https://conteudo.solutudo.com.br/birigui/ferias-antecipadas-como-ensinar-e-brincar-em-meio-a-pandemia-2/. Acesso em: 29 dez. 2020.

13 Disponível em: https://www.youtube.com/watch?v=Y10vCOXxtds\&t=13s\&ab_channel=Atilalamarino. Acesso em: 29 dez. 2020. 
6 Como podemos mapear a Covid-19 no mundo? a) Aprender aspectos relacionados à leitura de mapas; b) Refletir sobre diferentes questões mundiais que atravessam a pandemia da Covid-19; c) Explorar ferramentas de busca relacionadas às tecnologias digitais.

70 que as notícias de jornal dizem sobre a vacina da Covid-19?

a) Aprofundar os estudos sobre 0 gênero textual jornalístico; b) Refletir sobre a produção da vacina da Covid-19; c) Aprimorar o processo de leitura e escrita.
EF04MA16

EF04CI08

EF04GE10

EF04LP19

EF04LP15

a) Retomar conteúdos abordados ao longo da SD; b) Consolidar aprendizagens sobre a pandemia; c) Aprender, por meio da escuta/interação, a trabaIhar aspectos comunicacionais.
1) Aspectos geográficos da pandemia, a partir de mapas virtuais interativos, que mostram, em níveis locais, regionais, nacionais e mundiais, a propagação da Covid-19 e seus aspectos sociais. 2) Exploração de diferentes mapas pelos alunos (Google Maps, Google Earth, Tour Creator etc.).

1) Leitura de notícias antigas de jornais a respeito de campanhas de vacinação, em contraposição à leitura de notícias atuais sobre a produção da vacina da Covid-19, fomentando a discussão: 0 que é a vacina? Como é a sua produção? 2) Elaboração, pelos alunos, de uma fotolegenda anunciando a descoberta da vacina da Covid-19.

EF35LP20 EF35LP19 Realização de encenação teatral, em grupos de EF35LP18 4 ou 5 alunos, para integração das discussões realizadas. Para isso, poderão ser utilizadas imagens, sons, figurinos, cenários, textos, entre outros recursos. Tema da encenação: "Histórias da pandemia da Covid-19".

Fonte: autoria própria.

Na tabela 3 apresentamos uma proposta didática, elaborada com base em pressupostos de interdisciplinaridade e em uma perspectiva crítico-reflexiva de ensino. A partir dessa proposta buscamos refletir, por meio da integração de diferentes saberes, sobre as relações entre Ciência, Tecnologia e Sociedade.

Sobre as relações CTS, Santos e Mortimer (2001, p. 95) nos lembram que "As propostas curriculares para o ensino de ciência na perspectiva ciência, tecnologia e sociedade (CTS) possuem como principal meta preparar os alunos para o exercício da cidadania". Nessa perspectiva, considera-se que:

A ciência não é uma atividade neutra e 0 seu desenvolvimento está diretamente imbricado com os aspectos sociais, políticos, econômicos, culturais e ambientais. Portanto a atividade científica não diz respeito exclusivamente aos cientistas e possui fortes implicações para a sociedade. Sendo assim, ela precisa ter um controle social que, em uma perspectiva democrática, implica em envolver uma parcela cada vez maior da população nas tomadas de decisão sobre C\&T (SANTOS; MORTIMER, 2001, p. 96).

Compreendendo, então, que alfabetizar cientificamente implica na aquisição de conhecimentos que vão para além dos conceitos científicos, e que visam fornecer subsídios para que os sujeitos possam relacionar distintas formas de conhecimento às suas realidades, de modo a tomar decisões e expor seus posicionamentos críticos a respeito da sua relação com o mundo, propomos a SD exposta.

A proposta apresentada divide-se em oito momentos. Pautada nas habilidades da BNCC, a Tabela 3 apresenta as atividades nomeadas, intencionalmente, com títulos interrogativos, colocando uma espécie de questionamento-síntese aos alunos em cada um dos momentos em que inserimos uma nova questão sobre o tema vírus.

Cada atividade possui diferentes objetivos de aprendizagem, elaborados com base nas habilidades propostas pela BNCC para $04^{\circ}$ ano do ensino fundamental. Destarte, na aba "Descrição" foram colocadas duas ou três atividades em que serão desenvolvidas propostas diferentes, sendo que essas 
atividades envolvem abordagens como: a) pesquisa na web sobre a temática; b) elaboração de tabelas; c) exibição e elaboração de vídeos; d) leitura e interpretação de diferentes tipos textuais; e) realização de atividades práticas e lúdicas; f) interpretação e elaboração de gráficos para a compreensão matemática da contaminação ocasionada pela Covid-19; g) Compreensão de aspectos geográficos e sociopolíticos sobre a disseminação da Covid-19 no Brasil e no mundo; h) Compreensão da vacina e dos discursos midiáticos a ela relacionados; i) Síntese das aprendizagens por meio de diferentes linguagens.

Na primeira atividade didática proposta (N-1), inspirados nas sugestões do site "Nova Escola", propomos um questionamento inicial: "o que são os vírus?". A partir dessa interrogativa e de discussões ao seu respeito em sala de aula, sugere-se que o professor proponha aos alunos uma pesquisa comparativa. Assim, eles pesquisarão, comparando, os diferentes significados da palavra "vírus". Considerando que se trata de uma palavra polissêmica, que pode significar tanto no âmbito biológico, quanto no campo da informática, a proposição dessa pesquisa visa a elaboração de uma tabela (Tabela 4) pelos alunos para definir e caracterizar o termo. Adicionalmente, acredita-se que, ao compreender o significado da palavra, os alunos poderão compreender esse conceito na perspectiva da educação científica.

Tabela 4 - modelo de tabela para conceituações a respeito da palavra "vírus".

\begin{tabular}{l}
\hline \multicolumn{1}{c}{ Computador } \\
\hline Definição \\
Características \\
Formas de "prevenção" \\
\hline Fonte: adaptado da web-página "Nova Escola". Disponível em: https://bit.ly/3D9VyVR.
\end{tabular}

Na segunda atividade (N-2), objetivamos a compreensão da Biologia dos vírus e das similaridades e diferenças entre os vírus considerados como "comuns", tais como os vírus que causam gripes e resfriados, e o novo coronavírus, que causa a Covid-19. Para isso, propõe-se que seja exibido, e posteriormente discutido, os vídeos "Gripe e Resfriado", do médico Drauzio Varella, e o vídeo intitulado "COVID-19", do biólogo e influencer digital Átila lamarino. Após a apresentação e discussão dos aspectos biológicos e sociais por meio desses vídeos, sugere-se que seja solicitado aos alunos uma produção textual com informações sobre as principais diferenças, em termos de sintomas, formas de prevenção/tratamento e modos de transmissão, entre os dois: 0 vírus da gripe e 0 vírus da Covid-19. Essa atividade poderá ser feita a partir do planejamento e da execução de um vídeo-síntese sobre os vírus estudados em aula, que poderá ser gravado pelos alunos com o uso de ferramentas digitais.

$\mathrm{Na}$ terceira atividade da proposta (N-3) tem-se o objetivo de que, a partir de diferentes tipos textuais e de diferentes fontes de pesquisa, os alunos possam compreender as possíveis formas de busca por fontes fidedignas de informação, e assim consigam apreender novos conhecimentos sobre o novo coronavírus. A partir disso, pretende-se que, ao final da atividade, eles possam elaborar produções textuais informativas, a partir de narrativas pessoais. Ademais, os tipos textuais propostos para esse fim são: a) notícia de jornal; b) texto de divulgação científica; c) artigo científico; d) textos didáticos de Ciências, fornecidos pelo professor - aqui poderão ser disponibilizadas algumas páginas de um livro didático, por exemplo; e) manual com técnicas de higienização. Propõe-se, então, que seja pedido aos alunos que busquem, em grupos, esses diferentes tipos textuais, identificando a diferença entre eles, 
quanto aos seus estilos e formas de escrita ${ }^{14}$. Isso deverá ser feito com 0 auxílio do professor. Ao final, compreendendo as diferenças entre essas formas de textualização, visa-se que os alunos sejam capazes de elaborar breves notícias de jornal, de autoria própria, que contenham fatos hipotéticos e que retratem alguns aspectos relativos às mudanças em seus cotidianos durante a pandemia.

Na quarta atividade (N-4), propôs-se atividades lúdicas que visam a compreensão pelos alunos das formas de disseminação dos vírus. Assim, inspirados nas atividades do site "solutudo", poderão ser direcionadas discussões com base em dois experimentos. Num primeiro experimento, propõe-se que as crianças pintem as mãos com tinta guache de olhos vendados e, posteriormente, observem como a tinta pode se espalhar pelo seu corpo. Essa atividade visa demonstrar que, assim como 0 vírus pode se espalhar por qualquer superfície sem que possamos vê-los, dado que são seres microscópicos, um efeito semelhante ocorrerá ao vendarmos os olhos e brincarmos com a tinta. Já no segundo experimento, propõe-que que as crianças, com um lenço de papel fino, peguem uma beterraba cozida. Aqui a intenção é comparar quando elas soam o nariz e não lavam as mãos, pois, assim como a água da beterraba atravessa o papel e suja as mãos, os vírus também o fariam. Com base nesse método hipotético-dedutivo e experimental, poder-se-á solicitar como tarefa que as crianças elaborem um relatório científico a partir das respostas às seguintes questões: a) qual experimento nós fizemos? (introdução); b) por que fizemos? (objetivo); c) o que utilizamos para fazer esse experimento? (materiais e métodos); d) 0 que você observou durante 0 experimento (resultados e discussões); e) 0 que isso significa? (conclusão). Note que essas perguntas levam a reflexões comuns a relatório científicos, porém, com aspectos de ludicidade. Esse relatório poderá ser adaptado pelo professor.

$\mathrm{Na}$ quinta atividade (N-5), intenciona-se trabalhar com alguns aspectos vinculados ao conhecimento matemático. Para tal, sugere-se a construção de gráficos do tipo coluna ou pizza (a depender dos objetivos do professor) sobre questões pandêmicas. Nessa construção, os alunos deverão selecionar e sintetizar diferentes dados, a partir de buscas, em diferentes fontes, sobre informações referentes ao número de infectados pela Covid-19 no Brasil. Essas buscas poderão ser feitas em sites governamentais. Na elaboração dos gráficos sugere-se que os alunos construam legendas explicativas, voltadas à prevenção ao novo coronavírus. Como atividade motivadora, sugere-se que a aula comece com a apresentação da elaboração de gráficos sobre a pandemia, feita em um vídeo de Youtube pelo biólogo Átila lamarino. Acreditamos que essa atividade, que interliga questões matemáticas, biológicas e sociais, pode propiciar visões interessantes sobre 0 atual contexto.

Numa sexta atividade (N-6), propõe-se um trabalho que dialogue com questões da Geografia. Sugere-se assim que seja efetuada durante a aula a leitura de mapas. Assim, a intenção é trabalhar com aspectos geográficos da pandemia, a partir da apresentação de mapas virtuais interativos pelo professor, que mostram, em níveis locais, regionais, nacionais e mundiais, a propagação da Covid-19. A partir disso, tem-se a intenção de dialogar também sobre os demais aspectos sociais, econômicos, políticos, de saúde, entre outros envolvidos na questão. Como atividade final, sugere-se que haja tempo para que os alunos possam explorar diferentes mapas, como, por exemplo, aqueles presentes nas plataformas Google Maps, Google Earth, Tour Creator, entre outros.

Na sétima atividade proposta (N-7), sugere-se a leitura e interpretação de textos jornalísticos. Dessa maneira, propõe-se a leitura de notícias de jornal, de anos anteriores, referentes às campanhas de vacinação. Em contraposição, será feita a leitura de notícias de jornal, divulgadas na atualidade, sendo recomendados jornais de considerável expressão, em termos de circulação nacional,

14 Aqui entendido como recursos linguísticos, gráficos e/ou imagéticos que são comumente utilizados para a elaboração de cada um desses tipos textuais e que os classificam como pertencentes a um dado gênero. 
tais como, Folha de São Paulo, Estadão e 0 Globo ${ }^{15}$. As notícias a serem selecionadas seriam sobre a produção e distribuição da vacina contra a Covid-19. A partir dessas leituras, pretende-se fomentar a discussão a partir das seguintes questões: "0 que é a vacina? Como é a sua produção?". Como atividade final, poderá ser proposto que os alunos elaborem uma fotolegenda, anunciando o histórico momento em que foi finalizada a produção da vacina da Covid-19.

Na última atividade (N-8), se propõe a retomada de todos os conteúdos abordados ao longo da SD. Isso será feito de modo a consolidar as aprendizagens propiciadas a respeito do tema vírus e das questões que envolvem a pandemia da Covid-19. Essa retomada poderá ser proposta a partir da realização de atividades lúdicas de encenação teatral, realizadas em grupos de 4 ou 5 alunos que poderão utilizar-se de imagens, sons, textos, cenários, figurinos, entre outros recursos que ajudem na comunicação de suas aprendizagens. Como possibilidade, propõe-se uma encenação a partir do tema: "Histórias da pandemia da Covid-19".

Algumas reflexões se fazem interessantes diante dessa proposta de ensino. Considerando que no atual momento há uma série de discursos de ansiedade sobre a Covid-19, que circulam por meio das diferentes mídias, tal como apontado por Montalvão Neto, Moraes e Morais (2020), e levando em conta ainda que muitos são os impactos ocasionados por uma pandemia, como, por exemplo, a necessidade de isolamento/distanciamento social, a adoção de hábitos constantes de higiene e as muitas mudanças na rotina/cotidiano dos alunos, tal como o fechamento de escolas, com consequente início de aulas remotas, acreditamos que se torna fundamental esse tipo de proposição. Daí, a proposta de atividades, no âmbito do ensino, que possam orientar as pessoas a adotarem práticas preventivas, em caráter individual e visando também agregar ao coletivo, nos parece interessante. Essa mudança de posicionamento ocorrerá a partir da compreensão dos sujeitos sobre o próprio contexto em que estão imersos. Assim, ao entenderem o que significa este momento pandêmico a partir de questões científicas, tecnológicas e sociais, torna-se possível também a compreensão da importância de ações de distanciamento e de prevenção, bem como 0 seu impacto na sociedade.

Adicionalmente, compreendemos que 0 baixo índice de pesquisas na educação em Ciências sobre o tema "vírus", tal como mencionado, se torna um motivador para a elaboração de uma proposta deste tipo. Outrossim, pesquisas realizadas anteriormente pelos autores deste trabalho nos levaram a crer também que, abordagens que visam a formação de cidadãos com senso crítico sobre as questões científicas e tecnológicas, principalmente em meio à pandemia e ao volume de informações, credíveis e inverídicas (tais como as fake news e pós-verdades), se colocam como necessárias para a inserção dos alunos em uma cultura científica, possibilitando-Ihes a tomada de decisões e a participação democrática em decisões sobre questões sociocientíficas (MORAES; MONTALVÃO NETO; MORAIS, 2020, MONTALVÃO NETO et al., 2020, MONTALVÃO NETO; BAROLLI, 2021, entre outros).

Pesquisas como as de Silva Filho, Montalvão Neto e Rocha (2020) apontam para a necessidade de que se pense sobre os aspectos imediatos e pós-pandêmicos, mostrando assim uma crescente na produção de pesquisas sobre o Ensino Remoto Emergencial. Nessa perspectiva, consideramos que, sendo essa uma proposta de ensino (construção de uma SD), que emerge em meio ao contexto de Estágio Supervisionado, a proposição exposta tratou-se de um produto concernente às reflexões sobre "ser professor" em aulas de Ciências (MONTALVÃO NETO; MIGUEL, 2019), principalmente em meio a um contexto adverso pandêmico.

Com essas abordagens, acreditamos que foi possível trazer algumas reflexões sobre a importância de que sejam trabalhados, desde os anos iniciais do ensino fundamental, alguns aspectos 15 Disponível em: https://bit.ly/3pau8dG. Acesso em: 17 abr. 2021. 
sociocientíficos, concernentes a uma temática tão importante, como os vírus. Esse trabalho implica diretamente na formação do estudante e é feito a partir de reflexões que envolvem um conjunto de saberes, ou seja, em um diálogo transversal com distintos conhecimentos.

\section{CONSIDERAÇÕES FINAIS}

0 presente estudo teve como primeiro objetivo a compreensão da produção científica sobre a temática vírus, no âmbito da educação em Ciências, e como segundo objetivo a proposição de uma Sequência Didática. Ao confirmarmos a hipótese de que há uma relativa carência em relação à temática na pesquisa em educação e nas práticas de ensino, no que concerne às abordagens realizadas nos anos iniciais do ensino fundamental, averiguação essa que decorreu por meio de uma revisão de literatura no principal evento da área, o ENPEC, julgamos como necessária a elaboração de uma Sequência Didática que trouxesse perspectivas interdisciplinares, em caráter crítico-reflexivo. Essa proposta foi elaborada de modo que relacionasse aspectos concernentes à relação entre Ciência, Tecnologia e Sociedade.

Mediante os aspectos expostos, compreendemos que a abordagem da temática vírus, em diferentes perspectivas disciplinares e sociopolíticas, se coloca fundamental para a compreensão do atual momento pandêmico, bem como para a compreensão de questões pós-pandêmicas. A tomada de posicionamentos por parte de alunos a esse respeito, aliada à compreensão dos aspectos (socio)científicos que atravessam as questões da Covid-19, nos levam a crer que essa abordagem pode proporcionar não apenas o fomento aos hábitos de prevenção e de higiene, como também a assunção de posicionamentos críticos e a tomada de decisões conscientes por parte dos cidadãos frente aos impactos e desafios ocasionados por esta crise, que não apenas é sanitária, como também social.

A presente pesquisa se insere em um conjunto de reflexões que vêm sendo idealizadas pelos autores deste estudo e alia-se a um contexto formativo, relativo ao âmbito do Estágio Supervisionado em Pedagogia no qual foi criada. As explanações e propostas aqui expostas são iniciais e exploratórias. Nesse sentido, reconhecemos os limites da abordagem e consideramos que se fazem necessários outros trabalhos que tragam aspectos amplos sobre a pesquisa e 0 ensino da temática "vírus", principalmente nos anos iniciais do ensino fundamental. Todavia, consideramos que contribuímos para 0 campo da educação em ciências na medida em que, não apenas apontamos aspectos da produção científica sobre o tema de interesse, como também apresentamos uma possibilidade frente aos desafios enfrentados em meio à pandemia.

\section{REFERÊNCIAS}

ARAÚJO, I. C. N. ; ARAÚJO-JORGE, T. C.; MEIRELLES, R. M. S. Prevenção à dengue na escola: concepções de alunos do ensino médio e considerações sobre vias de informação. In: ENCONTRO NACIONAL DE PESQUISA EM EDUCAÇÃO EM CIÊNCIAS, 5, 2005, Bauru. Atas... Bauru: ABRAPEC, 2005. p. 1-12.

BARBIERO, A. C. N. ; SANTOS, E. D.; ALBANO, K. 0 Currículo na Educação Básica: contratempos no ensino com o contexto da pandemia Covid-19. In: Imagens do pensamento: sociedade hipercomplexa e educação remota. HABOWSKI, A. C.; CONTE, E. (Orgs.). 1 ed. São Paulo: Pimenta Cultural, 2020. p. 576-591. 
BRASIL. Base Nacional Comum Curricular - BNCC. Ministério da Educação. Secretaria da Educação Básica. Base nacional comum curricular. Brasília, DF, 2018. Disponível em: http://basenacionalcomum.mec.gov. br/\#/site/inicio. Acesso em: 23 dez. 2020.

FALKENBERG, M. B.; MENDES, T. P. L.; MORAES, E. P. ; SOUZA, E. M. Educação em saúde e educação na saúde: conceitos e implicações para a saúde coletiva, Rio de Janeiro, Ciência \& Saúde Coletiva, v. 3, n. 19, p. 847-852, 2014.

FONSECA, E. M.; FRANCO, R. M. Em tempos de Coronavírus: reflexões sobre a pandemia e possibilidades de abordagem no Ensino de Ciências a partir da Educação CTS. Research, Society and Development, Vargem Grande Paulista, v. 9 , n. 8, p. 1-19, 2020.

GIL, A. C. Métodos e técnicas de pesquisa social. 6. ed. São Paulo: Atlas, 2008.

KARAT, M. T.; BUSKO, P. S.; GIRALDI, P. M. Proposições para uma formação docente no ensino de ciências: 0 vírus zika e a epidemia de Microcefalia. Ensino \& Pesquisa, União da Vitória, v. 17, n. 3, p. 122-139, nov. /dez., 2019.

LOPES, L. H. L.; HENRIQUE, P. S. C.; BONATTO, M. P. O.; PINTO, J. S.; COLONESE, Paulo Henrique. Mundo unicelular: descobrindo a modelagem para abordar proporções microscópicas e saúde no Museu da Vida/Fiocruz. In: ENCONTRO NACIONAL DE PESQUISA EM EDUCAÇÃO EM CIÊNCIAS, 12., 2019, Natal/RN. Atas... Natal/RN: ABRAPEC, 2019. p. 1-10.

MOHR, A. A natureza da educação em saúde no ensino fundamental e os professores de ciências. Tese (Doutorado em Educação). Centro de Ciências da Educação. Universidade Federal de Santa Catarina, Florianópolis, 2002.

MONTALVÃO NETO, A. L. Discursos de Genética em Livro Didático: Implicações para o Ensino de Biologia. 209 f. Dissertação (Mestrado em Educação Científica e Tecnológica). Programa de Pós- graduação em Educação Científica e Tecnológica. Universidade Federal de Santa Catarina, Florianópolis, 2016.

MONTALVÃO NETO, A. L.; BAROLLI, E. Efeitos de sentido sobre transgênicos a partir da transformação nas condições de produção de leitura. Revista Brasileira de Educação em Ciências e Educação Matemática (ReBECEM), Cascavel/PR, v. 5, n. 1, p. 176-193, abr. 2021.

MONTALVÃO NETO, A. L.; MIGUEL, K. S. Práticas Cotidianas Escolares: Reflexões a partir da visão de licenciandos sobre "ser professor" mediante experiências no Estágio Supervisionado em Ciências. In: Educação: ressonâncias teóricas e práticas / SANTANA, W. K. F.; SILVEIRA, É. L. (Orgs.). 1 ed. São Carlos/SP: Pedro \& João Editores, 2019, v. 2, p. 204-219.

MONTALVÃO NETO, A. L.; MIGUEL, K. S.; SIMAS FILHO, J. P. , JUSTINA, L. A. D. A Educação de Jovens e Adultos em um cenário de pandemia: reflexões docentes. South American Journal of Basic Education, Technical and Technological, v. 8 , n. 1, p. 352-369, 2021.

MONTALVÃO NETO, A. L.; MORAES, F. N. ; MORAIS, Wanderson R. A produção da vacina da COVID-19: um olhar para 0 discurso de ansiedade veiculado pelas notícias de jornal. In: ENCONTRO DE DIVULGAÇÃO DE CIÊNCIA E CULTURA, 7, 2020, Campinas. Caderno de Resumos... Campinas: Unicamp, out. 2020, p. 73-75.

MONTALVÃO NETO, A. L.; ROCHA, G. G. S.; SIMAS FILHO, J. P. ; MACHADO, R. Ciência, fake news e pós-verdades: a produção de efeitos de verdade em tempos de pandemia. In: Encontro Virtual de Documentação em Software Livre e Congresso Internacional de Linguagem e Tecnologia Online, 14., 2020, Belo Horizonte. Anais... Belo Horizonte: UFMG, 2020, p. 1-8. 
MORAES, F. N. ; MONTALVÃO NETO, A. L.; MORAIS, W. R. A Biotecnologia no ensino: o não-lugar, silenciamentos e a escassez de materialidade histórica. In: Diálogos Plurais em Educação. BONFIM, D. A. et al. (Orgs.). 1. ed. Cruz Alta: Editora llustração, 2020, v. 1, p. 35-52.

NASCIMENTO, W. E.; MONTALVÃO NETO, A. L.; COMPIANI, M.; BAROLLI, E. Perspectivas educacionais curriculares no Ensino de Ciências: que discursos pautam às versões da Base Curricular Nacional do Ensino Fundamental? In: XII Encontro Nacional de Pesquisa em Educação em Ciências (ENPEC), 12., 2019, Natal-RN. Atas... Natal-RN: ABRAPEC, 2019.

OLIVEIRA, C. A. M.; BONATTO, M. P. 0. Vírus e modelagem para a educação em saúde: uma investigação no Parque da Ciência/Museu da Vida/Fiocruz. In: ENCONTRO NACIONAL DE PESQUISA EM EDUCAÇÃO EM CIÊNCIAS, 5, 2017, Florianópolis. Atas... Florianópolis: ABRAPEC, 2017. p. 1-9.

SANTOS, W. L. P. ; MORTIMER, E. F. Uma análise de pressupostos teóricos da abordagem C-T-S (Ciência - Tecnologia Sociedade) no contexto da educação brasileira. Ensaio - Pesquisa em Educação em Ciências, Belo Horizonte, v. 2, n. 2, p. 1-23, dez. 2002.

SANTOS, W. L. P. ; MORTIMER, E. F. Tomada de decisão para ação social responsável no ensino de ciências. Ciência \& Educação, Bauru, v. 7, n. 1, p. 95-111, 2001.

SASSERON, L. H.; CARVALHO, A. M. P. Almejando a alfabetização científica no ensino fundamental: a proposição e a procura de indicadores do processo. Investigações em Ensino de Ciências, Porto Alegre, v. 13, n. 3, p. 333-352, 2008.

STEPHENS, P. R. S. et al. Virologia. In: AMENDOEIRA, M. Conceitos e métodos para a formação de profissionais em laboratórios de saúde. 1. ed., EPSJV, Rio de Janeiro: Editora Vozes, v. 4, 2009, p. 125-220.

SILVA, D. A.; FERREIRA, A. G. Diálogos em Educação do Campo - Ciências da Natureza através de uma questão sociocientífica em diferentes espaços educativos. Revista Interdisciplinar Sulear, n. 10, p. 27-37, 2021.

SILVA FILHO, J. G.; MONTALVÃO NETO, A. L.; ROCHA, G. G. S. A produção acadêmica sobre o ensino remoto emergencial (ERE) em meio a pandemia da Covid-19: Perspectivas e tendências. In: Escritos de educação: perspectivas e tendências / org.: SCHÜTZ, J. A. et al., 1 ed., Cruz Alta: Ilustração, 2020, v. 2. p. 203-216.

ZABALA, A. A prática educativa: como ensinar. Porto Alegre: Artmed, 1998.

WERNECK, G. L.; CARVALHO, M. S. A pandemia de COVID-19 no Brasil: crônica de uma crise sanitária anunciada. Cadernos de Saúde Pública, v. 36, n. 5, p. 1-4, 2020.

RECEBIDO EM: 13 maio 2021

CONCLUÍDO EM: 29 out. 2021 